\title{
Analysis of Ensuring Thermal Comfort Using an Intelligent Control System
}

\author{
Zuzana Kolková1,*, Peter Hrabovský1 ${ }^{1}$, Zuzana Florková $^{1}$, and Richard Lenhard ${ }^{2}$ \\ ${ }^{1}$ University of Žilina, Research centre, Univerzitná 8215/1, 01026 Žilina, Slovakia \\ ${ }^{2}$ University of Žilina, Department of Power Energy, Univerzitná 8215/1, 01026 Žilina, Slovakia
}

\begin{abstract}
Intelligent buildings are productive, energy efficient and environmentally acceptable. Intelligent buildings should be health, permanent and technologically advanced. It is necessary to predict the development and selection of suitable systems for the thermal comfort for ensure of the thermal comfort in the workplace. It is important to analyse how many thermal factors will affect the population, room temperature uniformity, asymmetry of the radiation temperature and turbulence intensity of the flowing air. Thermal comfort is given by the radiant heat, air temperature, air velocity and relative humidity in the room. The main impact of these factors on the comfort level of individuals depends on the type of clothing and on activity. The wrong thermal comfort is detrimental to workers' health, affects adverse effects on the psyche and increasing the risk of accidents. The thermal comfort of people can be achieved by intelligent management of energy systems in the buildings. The measurement results and settings of intelligent systems are presented in this article.
\end{abstract}

\section{Introduction}

The intelligent building control is based on communication with all embedded system devices in the form of data messages sent by the data cable. Sensors, thermostats, motion sensors, fire detectors are designed to monitor the situation and then send the measured data to the database. The primary unit will send a command that accepts and executes the requested operation. The dimmers, binary outputs, power switches are among the actuators. Changes to the control system or its deployment can be realized without the necessity of reworking the project or installing new cables. Changes to an existing system can be made after several years [1].

Communication between the devices involved in the control system with each other and with the control system ensures its proper functioning. This connection can be secured by cable or wireless. The benefits of cable connection include high speed, cost and availability of the devices needed for the connection. It is the most used connection because of the connection of electrical equipment to the devices [2], [3].

\footnotetext{
* Corresponding author: zuzana.kolkova@rc.uniza.sk
} 


\section{Energy and control systems}

Heating and cooling are used to create thermal comfort in the building. Electric heat pumps ground - water, air - water and gas heat pump air - water are used for heating and cooling. The main objective is to understand the functioning of all intelligent building systems and ensure optimal use of all energy sources. Heat pumps use heat from the environment either through boreholes from the ground or from the air. The intelligent building has 10 boreholes. Each borehole has 100 meters. Heat can also earn seasonal rooftop solar tube collectors. In the extreme case is used gas boiler. Cold is obtained directly from boreholes. Cooling and heating are possible in all the settings for research purposes. Section of the light and blinds is also used to create thermal comfort of people in the building. LED light sources are used, part is bionic. Blinds eliminate excessive dazzle in con-junction with lighting. The desired light intensity can be adjusted separately for each room. Lighting in hallways and bathroom is automatic. Classical switches are also used in technical premises. Section of ventilation and air conditioning provides ventilation in the building. Three air handling units (on the roof) using for this function. Regulation is centralized and automated. It is possible to control the flaps to the nearest room. Ventilation in sanitary facilities is an automatic under pressure. Cooling of server rooms and DAT Centre is independent and automatic (5 units). Through central control and monitoring intelligent building can monitor and control individual components collect data in real time and from a database. It serves as a support for projects and research tasks. Management is based on software tools that are an extension of the management processes of the building. Point of contact is a SCADA or OPC server. Display information about experiments, availability of equipment, laboratories are located in front of each room. Additional technologies include elements built into the construction of buildings. Pressure, temperature, humidity, radiation and wind speed are part of these technologies. Intelligent building have also camera system, sensor of lighting in the room and the presence of persons in the building, fire detector FES, fire button FES and fire alarm FES.

Central management programs run on internal servers and workstations of the university, data repositories, and in an internally doubled separated LAN network with a connection to the external communication and computing infrastructure of the school. The system is controlled through the BACnet (Building Automation Control Network) open communication standard. Regulators and automation stations communicate with this interface. External environmental conditions are recorded by the weather station, which is located on the building. It is possible to set individual parameters for each room individually or for one floor or for the whole building.

\section{Thermal comfort}

The intelligent control system ensures thermal comfort in the workplace. It is important to find the optimal settings for each system. The human body is a continuous source of heat. This metabolic heat production is divided into basal and muscle metabolism. Basic metabolism is the heat produced by biological processes. Muscle metabolism arises in human activity. Heat produced by the organism must be taken to the environment or body temperature changes. The temperature inside the human body is around $37^{\circ} \mathrm{C}$, while the skin temperature may range from 31 to $34{ }^{\circ} \mathrm{C}$ depending on the surrounding environment. Differences arise over time but also by parts of the human body [4].

Indoor environments in buildings create many components. Thermal humidity, smell, aerosol, microbial and acoustic components are essential. The basic influence on people has the thermal humidity parameters of the living room. In terms of impact on human health, air 
quality seems to be the most important factor. Most of these environmental components are affected by ventilation [5].

Space temperature uniformity, asymmetry of the radiation temperature, and turbulence intensity of the flow air affect thermal comfort. People are capable of detecting heat and they can feel changes in temperature globally on the entire surface of the body but also locally on body parts. It has been shown that humans can acclimate to ambient temperature physiologically and psychologically. It is therefore important to address the issues of thermal comfort in the interiors (buildings) and to experimentally determine a suitable way of creating the optimal conditions of the environment. The goal is to ensure a sense of satisfaction from the environment and also to increase work performance and a sense of comfort. We use the Dantec ComfortSense system to investigate operating conditions [6].

ComfortSense is a multichannel system for measurement air velocity and air temperature, humidity and operative temperature. It calculates statistical values - Draught rate (DR), Predicted Mean Vote (PMV) and Predicted Percentage Dissatisfied (PPD). ComfortSense can be used for many applications including HVAC research and development, testing of ventilation equipment, building research, passenger comfort studies in the automotive and aviation industries. Thermal comfort measurements with ComfortSense comply with International Standards EN 13182, ISO 7726, 7730, ASHRAE standard 113 and ASHRAE standard 55 [7].

ASHRAE Standard 55 (Thermal Environmental Conditions for Human Occupancy) is a standard that provides minimum requirements for acceptable thermal indoor environments. It establishes the ranges of indoor environmental conditions that are acceptable to achieve thermal comfort for occupants. Percent dissatisfied (PD) represent percentage of people predicted to be dissatisfied due to local discomfort. Predicted mean vote (PMV) is an index that predicts the mean value of the votes of a large group of persons on the seven point thermal sensation scale. Predicted percentage of dissatisfied (PPD) is an index that establishes a quantitative prediction of the percentage of thermally dissatisfied people determined from PMV [8].

\section{Measurement in the real conditions}

The measurement was carried out in the Research Centre of the University of Žilina in July. The room is located on the first floor on the southwest side. The room is located in the middle of the building. The room has a rectangular floor plan with dimensions of $3.40 \times 5.70 \times 3.00 \mathrm{~m}$.

All intelligent control systems are installed in the room. There is a room sensor, $\mathrm{CO}_{2}$ sensor, humidity sensor, fire sensor, open window sensor, temperature sensor and lighting sensor. The windows are fitted with external blinds with the function of shading according to the intensity of solar radiation.

Heating is provided by underfloor heating. Cooling is provided by an acoustic cooling ceiling and a central ventilation system with support for heating and cooling. The influence of intelligent control system on ensuring optimal operating conditions in space - thermal comfort has been studied. Two basic types of cooling system settings have been investigated. Setting the intelligent control system for the cooling section was $22{ }^{\circ} \mathrm{C}$ (home position) and system off (simulates a no-use state control system).

The positions of the measuring probes are located in the living areas. These are known places of residence of workers. These places are defined as workstations or seating positions depending on the function of the space. Measurements shall be made at locations where the extremely high values of thermal parameters are estimated or observed. 
The operating temperature is measured or calculated at 0.6 meter for seated persons and 1.1 meter for standing persons.

The insulation value of the clothing determines the resistance to appreciable heat transfer depending on the clothing. It is expressed in units of CLO (unit for quantifying the insulation provided by clothing and its components $\left.1 \mathrm{CLO}=0.155 \mathrm{~m}^{2} .{ }^{\circ} \mathrm{C} . \mathrm{W}^{-1}\right)$. The human isolation value was set at $0.8 \mathrm{CLO}$ for office work. The level of human activity determines the level of transformation of chemical energy into thermal and mechanical work. It is expressed in units of MET $=58.2 \mathrm{~W} \cdot \mathrm{m}^{-2}$, which is the energy produced per unit area of the skin area of an average person sitting still. The level of human activity was 1.2 MET for the work activity performed in the office space. This value was determined based on the calculation capabilities of ComfortSense.

The following figures show graphical measurement results for various settings of the intelligent energy monitoring system (Figure 1 - Figure 4.). The main parameters that were measured are the outdoor temperature, the operating temperature in the room and the setting of the intelligent control system for the cooling sections in the summer.

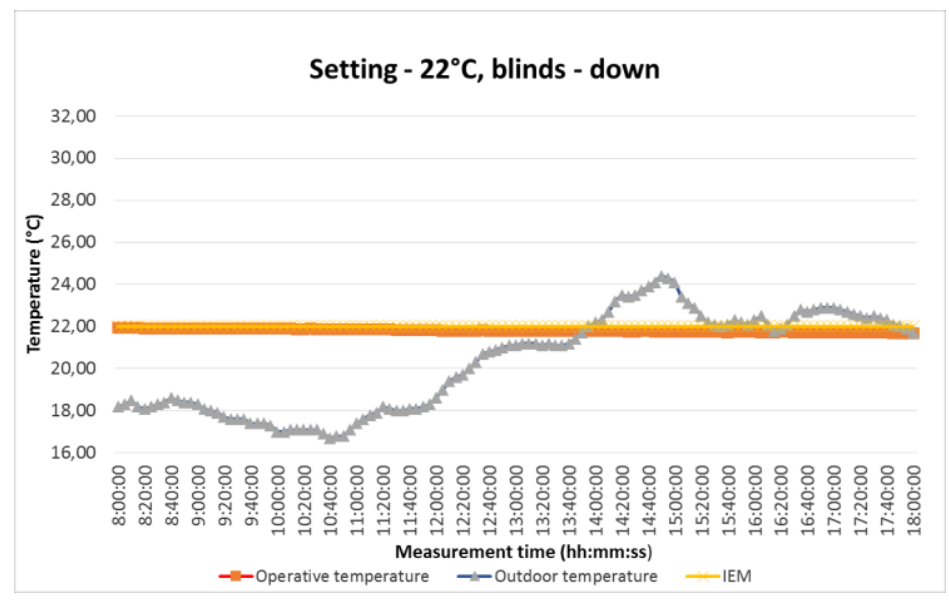

Fig. 1. Indoor temperature in room $22^{\circ} \mathrm{C}$ and blinds in down position.

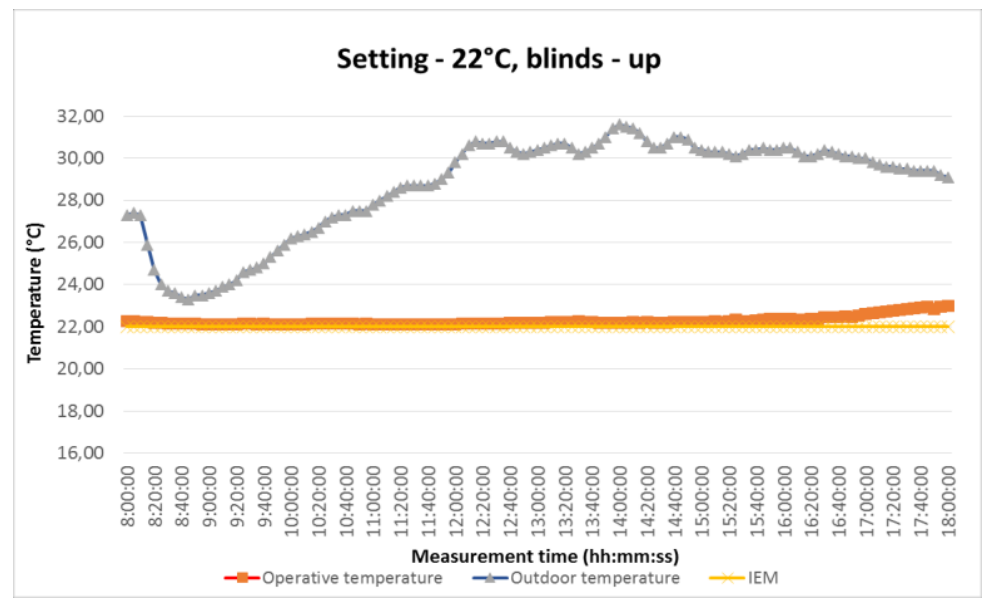

Fig. 2. Indoor temperature in room $22{ }^{\circ} \mathrm{C}$ and blinds in up position. 


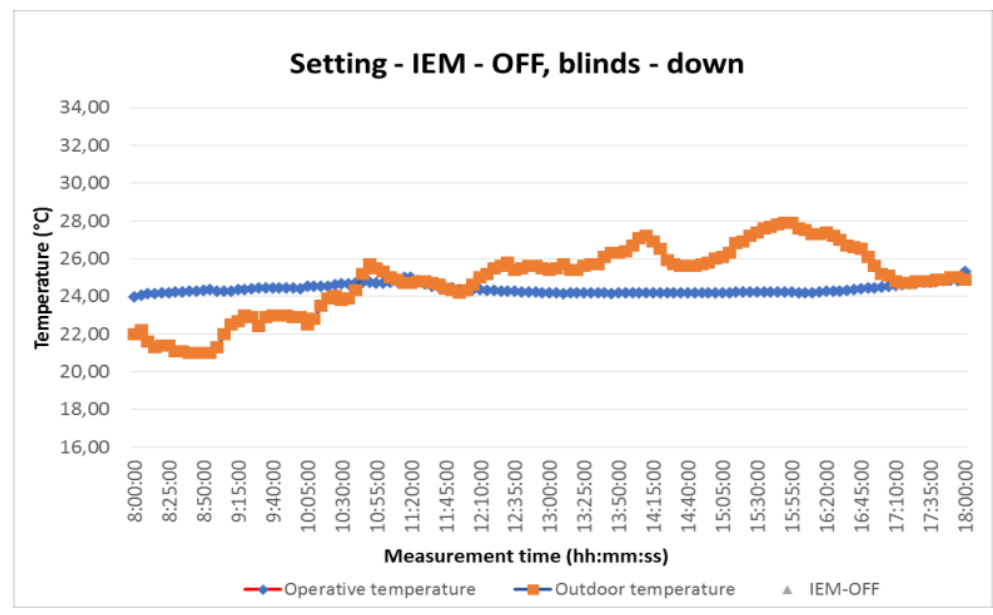

Fig. 3. Indoor temperature without intelligent energy monitoring and blinds in down position.

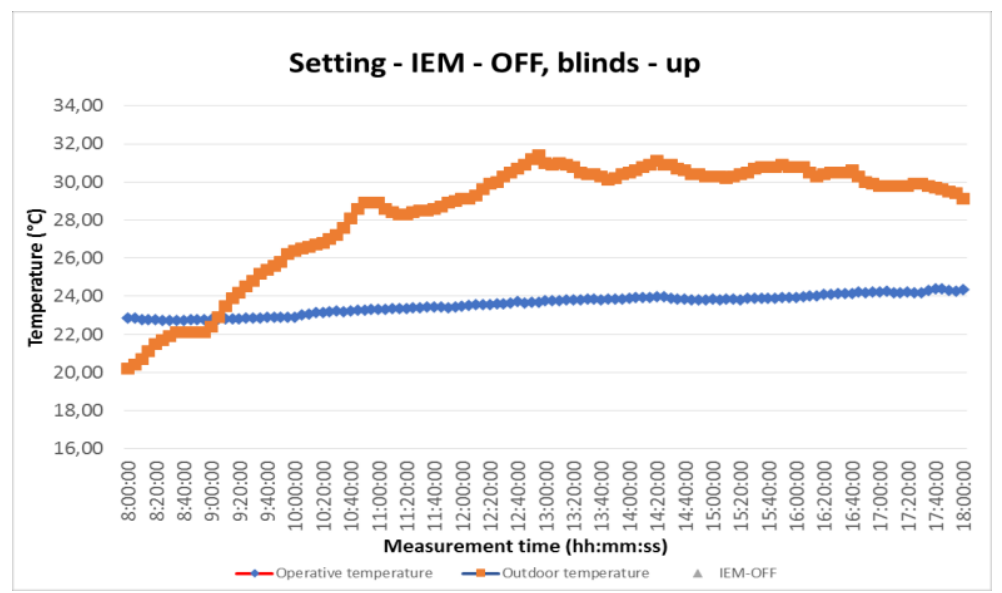

Fig. 4. Indoor temperature without intelligent energy monitoring and blinds in up position.

PMV and PPD parameters were also evaluated in the evaluation of the impact of the working environment on the thermal comfort of workers. These parameters determine the mean warmth of a group of people and the predicted percentage of dissatisfaction with the operating conditions (Figure 5 - Figure 6.). They are designed for each measurement day with respect to the setting of the intelligent control system. 

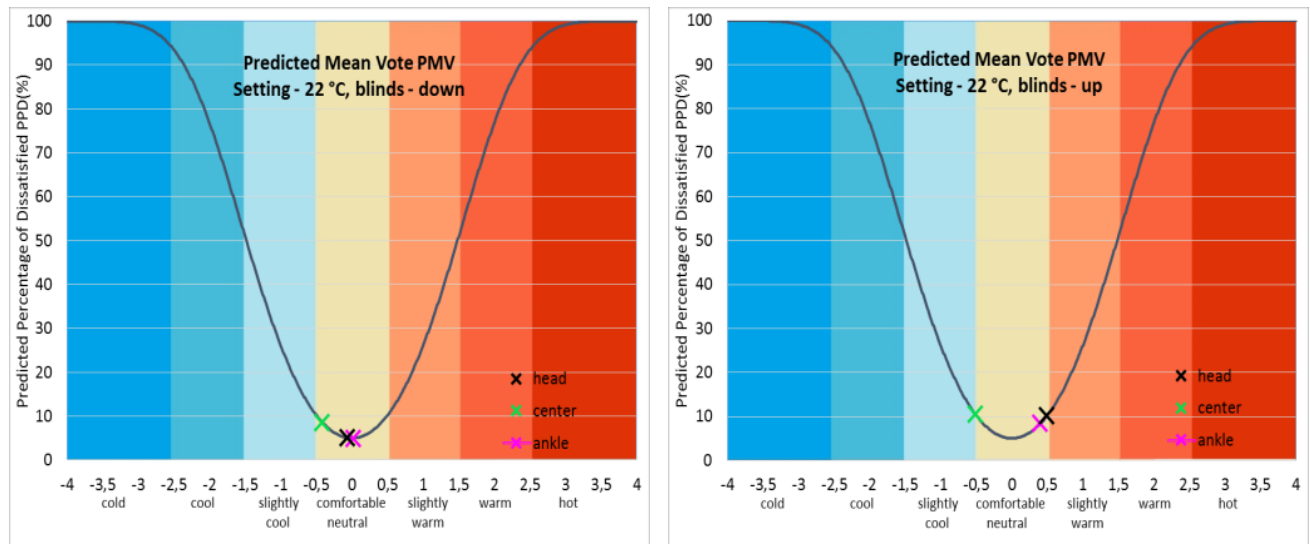

Fig. 5. PMV and PPD parameters - indoor temperature $22^{\circ} \mathrm{C}$.
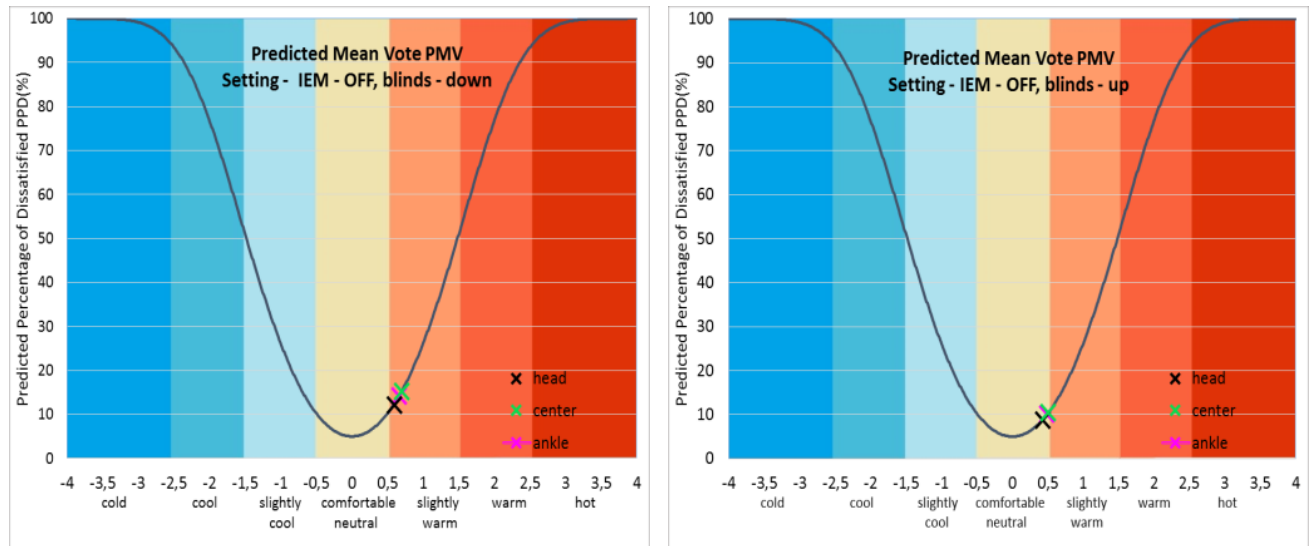

Fig. 6. PMV and PPD parameters - IEM OFF.

\section{Conclusion}

The position of the blinds was also evaluated in two positions. The two main positions were evaluated: the up position and the down position. The intelligent control system can adjust the blinds in seven other positions, which will be subject to further investigation. The measurement graphs show the influence of the blinds when the intelligent control system is switched.

Thermal comfort is ensured in the range of optimal values of operative temperature, including the values of other microclimatic variables. Mild temperature discomfort is expressed by the range of acceptable operating temperature values, including the values of other microclimatic variables. The range of optimal, permissible values of operating temperature and other microclimatic variables depends on the total energy expenditure of the organism (work class) and is determined for the warm and cold period of the year.

The optimum temperature is the range of temperatures that the employer should strive to maintain at his workplace all year round. The permissible temperature is a limit value that the workplace temperature should not exceed even if the employer is unable to maintain optimal temperatures. The optimum operating temperature range in the office 
space is set at $23-27^{\circ} \mathrm{C}$. This condition was not exceeded in any of the room settings examined. In all cases, the PMV and PPD parameters are comfortable - neutral. When the system is turned off, the PMV and PPD parameters get to slightly warm. In the next measurement, the effect of rotating the blinds in different settings and time intervals will also be evaluated.

Acknowledgements: „This work was supported under the project of Operational Programme Research and Innovation: Research and development activities of the University of Zilina in the Industry of 21 st century in the field of materials and nanotechnologies, No. 313011T426. The project is cofunding by European Regional Development Fund“, KEGA-063ŽU-4/2018 „Depositing hydrocarbon gases into hydrate structures as an alternative energy storage method.

\section{References}

1. B. Garlík, Inteligentní budovy (BEN - technická literature, vydaní 1. české, 325 (2012)

2. S. H. Wang, Intelligent Buildings and Buildings Automation (Routledge, 1. Edition), pp. 264 (2009)

3. D. CLEMENTS-CROOME Intelligent buildings: An introduction (Routledge, 1. Edition) pp. $232(2013)$

4. http://vetrani.tzb-info.cz/vnitrni-prostredi/404-tepelna-pohoda-a-nepohoda

5. http://vetrani.tzb-info.cz/vnitrni-prostredi/2650-vnitrni-prostredi-budov-a-tepelna-pohodacloveka

6. STN 73 0540-3:2012: Tepelná ochrana budov. Tepelnotechnické vlast-nosti stavebných konštrukcií a budov. Čast' 3: Vlastnosti prostredia a stavebných výrobkov (2012)

7. http://shop.iccsafe.org/media/wysiwyg/material/8950P219-sample.pdf

8. https://www.researchgate.net/figure/282479241_fig1_Fig-1-Thermal-sensation-scale -a- MCIMcIntyre-Index-b-ASH-ASHRAE-thermal 